\title{
KARAKTERISTIK DAN DAMPAK MAKROALGA INTRODUKSI
}

\author{
Oleh \\ Tri Handayani ${ }^{1)}$
}

\section{ABSTRACT}

CHARACTERISTIC AND IMPACTS OF INTRODUCED MACROALGAE. An introduced macroalgae is species of macroalgae that have been introduced beyond its native range through human activities and has become successfully established in the new locale. Introduced macroalgae have an impact on ecology and evolution, i.e. direct and indirect competitions with native biota (space monopolization and change in community composition), effects on higher trophic levels (herbivores, associated fauna, toxicity), habitat change (changed structure, sediment accumulation), change of ecosystem processes (alteration of trophic structure) and genetic effects. Introduced macroalgae also have an impact on economy and social, i.e. costs of loss of ecosystem functions or values, impacts on environmental amenity, impacts on human health, management costs (government/non-government), costs of research into introduced species, costs for eradication and control measures and costs for education/extension campaigns. Management of impact and research are needed to minimize the impact of introduced macroalgae.

\section{PENDAHULUAN}

Makroalga merupakan salah satu komponen penyusun ekosistem pesisir yang berperan baik secara ekologi terhadap ekosistem, maupun secara ekonomi bagi manusia. Peranan makroalga dalam ekosistem merupakan produser primer dalam rantai makanan, dan penghasil oksigen bagi kehidupan organisme ekosistem pesisir. Beberapa makroalga menjadi habitat bagi organisme laut kecil lainnya (krustasea, moluska dan ekinodermata) untuk berlindung dari arus dan predator, serta sebagai sumber makanan bagi organisme laut (Williams \& Smith, 2007; Patreph et al., 2011; Satheesh \& Wesley, 2012). Peranan makroalga yang sangat penting bagi ekosistem pesisir membuktikan bahwa keberadaan makroalga sangat penting untuk keseimbangan ekosistem pesisir itu sendiri. Peranan makroalga secara ekonomi, antara lain penghasil fikokoloid seperti alginat, agar-agar dan karaginan (Rasmussen \& Morrissey, 2007; Holdt \& Kraan, 2011). Selain itu, makroalga juga menghasilkan polisakarida bioaktif yang bermanfaat untuk bidang kesehatan dan farmasi (Morrissey et al., 2001; Holdt \& Kraan, 2011). Pemanfaatan makroalga tersebut menyebabkan peningkatan jumlah kebutuhan material makroalga untuk pemenuhan kebutuhan manusia. Salah satu cara untuk pemenuhan kebutuhan makroalga adalah melalui budidaya makroalga. Makroalga yang dibudidaya dapat berupa jenis asli

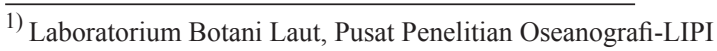


maupun jenis introduksi. Makroalga introduksi dibawa dari daerah lain untuk dikembangkan.

Sampai saat ini masyarakat Indonesia pada umumnya hanya mengetahui bahwa makroalga introduksi tersebut dibudidayakan untuk memenuhi peningkatan kebutuhan. Sedikit yang memahami bahwa makroalga introduksi dapat melalui perantara kegiatan budidaya atau dapat melalui perantara lainnya, bagaimana karakteristik makroalga introduksi tersebut, bagaimana dampaknya makroalga introduksi terhadap ekosistem dan bagaimana mengatasi dampak yang telah ditimbulkan oleh makroalga introduksi tersebut. Oleh karena itu, tulisan ini akan membahas bagaimana karakteristik dan dampak makroalga introduksi terhadap keberlangsungan ekosistem pesisir.

\section{KARAKTERISTIK MAKROALGA INTRODUKSI}

Spesies makroalga introduksi didefinisikan sebagai spesies yang termasuk Phyla yaitu Charophyta, Chlorophyta, Ochrophyta (dahulu disebut Phaeophyta) atau Rhodophyta yang telah didatangkan dari luar daerah asalnya yang jauh secara geografis melalui aktivitas manusia dan spesies tersebut sukses tumbuh, berkembang dan menetap di daerah yang baru (Williams \& Smith, 2007).

Makroalga introduksi masuk di daerah yang baru dapat melalui beberapa perantara, antara lain: (1) budidaya (mendatangkan makroalga secara sengaja untuk keperluan budidaya), (2) aquarium introduction (lepasnya makroalga dalam suatu akuarium ke alam bebas secara tidak sengaja), (3) budidaya kerang-kerangan (masuknya makroalga yang tumbuh pada atau berasosiasi dengan budidaya kerang secara tidak sengaja), (4) Pemberat (propagul terangkut dalam pemberat atau melekat pada pemberat), (5) lambung kapal (spesies makroalga melekat pada lambung kapal yang melintas antar samudera), (6) alat tangkap (spesies makroalga tersangkut pada alat tangkap sehingga spesies yang bersangkutan dapat berpindah dari satu lokasi ke lokasi lainnya) dan (7) penelitian (spesies makroalga sengaja didatangkan dari lokasi asli ke lokasi tertentu untuk tujuan penelitian) (Williams \& Smith, 2007).

Sampai saat ini diperkirakan terdapat sebanyak 277 spesies makroalga introduksi di seluruh dunia yang terdiri dari 165 spesies Rhodophyta (makroalga merah), 66 spesies Ochrophyta (makroalga coklat), 45 spesies Chlorophyta (makroalga hijau) dan satu spesies Charophyta. Sebagian besar makroalga introduksi tersebut merupakan spesies invander yaitu spesies yang menjajah daerah di luar distribusi biogografi aslinya (Williams \& Smith, 2007). Makroalga introduksi tersebut, selain dikelompokkan berdasarkan phyla juga dapat dikelompokkan berdasarkan kelompok fungsional antara lain: filamentous, crustose, corticated foliose, corticated macrophyte, leathery macrophyte, articulated calcareous, dan sipohonous (Steneck \& Dethier, 1994). Jumlah makroalga introduksi berdasarkan kelompok fungsionalnya dan perantara masuknya makroalga introduksi dapat dilihat pada Gambar 1. 
a

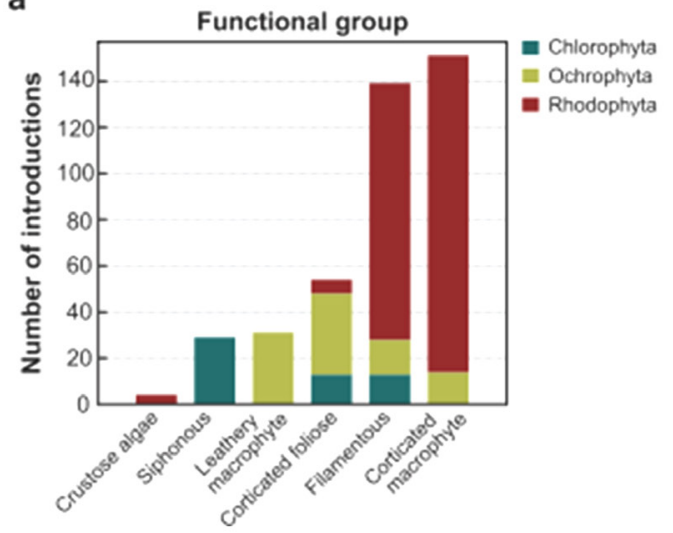

b

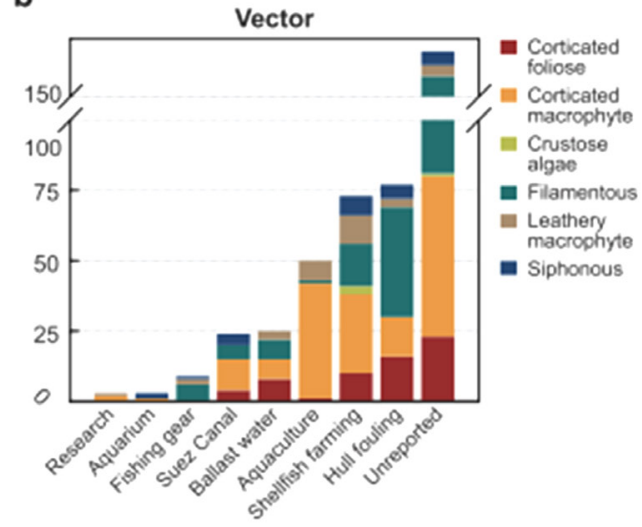

Gambar 1. Jumlah makroalga introduksi berdasarkan (a) kelompok fungsional dan phyla makroalga, dan (b) perantara masuknya makroalga introduksi (Williams \& Smith, 2007).

Makroalga introduksi yang berasal dari Chlorophyta, didominasi oleh empat famili yaitu: Derbesiaceae, Codiaceae, Ulvaceae, dan Caulerpaceae (Williams \& Smith, 2007). Chlorohyta yang masuk dalam kategori makroalga introduksi antara lain: Codium fragile, Caulerpa racemosa, Caulerpa taxifolia, Caulerpa cylindracea, Cladophora cericea, Chaetomorpha dan Ulva (Smith et al., 2002; Schaffelke \& Hewitt, 2007; Williams \& Smith, 2007; Bulleri et al., 2016).

Makroalga introduksi dari kelompok Ochrophyta, didominasi oleh empat famili yaitu: Chordariaceae, Alariaceae, Sargassaceae dan Fucaceae (Williams \& Smith, 2007). Makroalga coklat yang termasuk kategori makroalga introduksi antara lain: Punctaria, Sphaerotrichia, Asperococcus, Leathesia, Undaria pinnatifida, Sargassum muticum, Fucus evanescens, Ectocarpus, Stictyosiphon dan Hydroclathrus clatratus (Arenas et al., 2002; Smith et al., 2002; Schaffelke \& Hewitt, 2007; Williams \& Smith, 2007).

Makroalga introduksi yang berasal dari Rhodophyta, berasal dari beberapa famili yaitu: Rhodomelaceae, Ceramiaceae,

Gracilariaceae, Solieriaceae, Cystocloniaceae, Corallinaceae, Delessariaceae, dan Areschougiaceae (Williams \& Smith, 2007). Makroalga merah yang termasuk kategori makroalga introduksi antara lain: Hypnea musciformis, Gracilaria vermicolophylla, Gracilaria salicornia, Kappaphycus alvarezii, Eucheuma denticulatum, Eucheuma striatum, Acanthophora spicifera, Polysiphonia, Womersleyella dan Sarconema (Nyberg, 2007; Schaffelke \& Hewitt, 2007; Williams \& Smith, 2007; Thomzen et al., 2013). 


\section{DAMPAK MAKROALGA INTRODUKSI}

Makroalga introduksi memberikan dampak yang sangat beragam, namun dapat kita kelompokkan menjadi dua garis besar yaitu (1) dampak secara ekologi dan evolusi, dan (2) dampak secara ekonomi dan sosial. Informasi mengenai dampak ekonomi merupakan gabungan biaya penilaian kuantitatif dan upaya pengendalian serta mengatasi dampak yang ditumbulkan (Schaffelke \& Hewitt, 2007).

\section{Dampak Secara Ekologi}

Pengaruh makroalga introduksi pada umumnya berkaitan dengan hubungan kompetisi pada habitat penerima (resipient habitat). Bentuk kompetisi tersebut, secara umum ditunjukkan dengan kelimpahan tinggi dari spesies introduksi, monopoli dan mengurangi kelimpahan/biomassa makroalga asli atau lamun. Dampak makroalga introduksi menyebabkan terjadinya kompetisi secara langsung maupun tidak langsung terhadap spesies asli, misalnya kompetisi mendapatkan cahaya dan substrat, sehingga terjadi monopoli dan perubahan struktur komunitas (Schaffelke \& Hewitt, 2007). Makroalga introduksi juga memberikan dampak pada level tropik yang lebih tinggi (misalnya herbivora, fauna asosiasi dan toksisitas) (Schaffelke \& Hewitt, 2007; Thomsen et al., 2013), perubahan habitat (perubahan struktur dan akumulasi sedimen), perubahan proses-proses ekosistem (perubahan struktur tropik) dan dampak secara genetik (interspesies berupa intrograsi dan intraspesies berupa hibridisasi) (Schaffelke \& Hewitt, 2007). Menurut Williams \& Smith (2007), makroalga introduksi memberikan dampak terhadap kelimpahan, struktur dan fungsi komunitas, keanekaragaman, pola makan dan performa biota-biota penyusun ekosistem (Gambar 1).

Makroalga introduksi memberikan dampak pada penurunan kelimpahan biota asli. Fenomena ini terjadi sekitar 40\% dari kasus keberadaan makroalga introduksi di suatu area. Penelitian secara eksperimental tentang makroalga introduksi menunjukkan dampak negatif (48\% atau 76 kasus), terutama dampaknya terhadap makroalga asli. Dampak lainnya adalah terjadinya perubahan struktur komunitas (8\% atau 16 kasus)(Williams \& Smith, 2007). Dampak ekologi 17 spesies dari 277 spesies makroalga introduksi yang sudah dipelajari, antara lain adalah Caulerpa taxifolia, Undaria pinnatifida, dan Sargassum muticum (Wikstrom et al., 2006; Williams \& Smith, 2007). Selain memberikan dampak negatif, makroalga introduksi juga memberikan dampak positif secara ekologi. Dampak positif dan negatif keberadaan makroalga introduksi dapat dilihat pada Tabel 1 dan Gambar 2. 
Tabel 1. Dampak ekologi terhadap kehadiran makroalga introduksi.

\begin{tabular}{|c|c|c|c|}
\hline Makroalga Introduksi & Dampak & Respon & Sumber Pustaka \\
\hline \multirow{2}{*}{ Caulerpa racemosa } & Negatif & $\begin{array}{lr}\text { Tutupan } & \text { makroalga } \\
\text { i } \mathrm{n} \mathrm{t} \mathrm{r} \mathrm{o} \mathrm{d} \mathrm{u} \mathrm{k} \mathrm{s} \mathrm{i} \\
\text { keragaman } \\
\text { kekayaan } \\
\text { makroalga }\end{array}$ & $\begin{array}{l}\text { Piazzi et al. (2001); } \\
\text { Piazzi et al. (2003) }\end{array}$ \\
\hline & Positif & $\begin{array}{l}\text { Kekayaan jenis } \\
\mathrm{m} \text { a k r o f a u n a } \\
\text { dan polikaeta, } \\
\text { produktivitas primer } \\
\text { lamun }\end{array}$ & $\begin{array}{l}\text { Argyrou et al. } \\
\text { (1999); Dumay et al. } \\
\text { (2002) }\end{array}$ \\
\hline \multirow[t]{2}{*}{ Caulerpa taxifolia } & Negatif & $\begin{array}{l}\text { Biomasa lamun, } \\
\text { f o t o s i n t e s i s } \\
\text { makroalga, kekayaan } \\
\text { jenis makroalga, } \\
\text { kekayaan jenis ikan }\end{array}$ & $\begin{array}{l}\text { Williams \& Grosholz } \\
\text { (2002); Ferrer et al. } \\
\text { (1997), Piazzi et al. } \\
\text { (2003); York et al. } \\
\text { (2006). }\end{array}$ \\
\hline & Positif & $\begin{array}{l}\text { Fiksasi nitrogen, } \\
\text { produktivitas } \\
\text { lamun }\end{array}$ & $\begin{array}{l}\text { Chisholm \& Moulin } \\
\text { (2003); Dumay et al. } \\
\text { (2002) }\end{array}$ \\
\hline Codium fragile & Negatif & $\begin{array}{l}\text { Kelangsungan hidup } \\
\text { lamun }\end{array}$ & Garbary et al. (2004) \\
\hline \multirow{2}{*}{ Sargassum muticum } & Negatif & \begin{tabular}{ll|}
$\begin{array}{l}\text { Kekayaan jenis } \\
\text { makroalga }\end{array}$ & \\
\end{tabular} & Stæhr et al. (2000) \\
\hline & Positif & $\begin{array}{l}\text { Produktivitas primer, } \\
\text { dekomposisi }\end{array}$ & $\begin{array}{l}\text { Pedersen et al. } \\
(2005)\end{array}$ \\
\hline \multirow{2}{*}{$\begin{array}{l}\text { Acanthophora spicifera } \\
\text { Gracilaria salicornia, } \\
\text { Kappaphycus alvarezii }\end{array}$} & Negatif & $\begin{array}{l}\text { Perubahan perilaku } \\
\text { makan ikan }\end{array}$ & Stimson et al. (2001) \\
\hline & Positif & $\begin{array}{l}\text { Perubahan perilaku } \\
\text { makan ikan }\end{array}$ & Stimson et al. (2001) \\
\hline $\begin{array}{l}\text { Eucheuma denticulatum } \\
\text { Kappaphycus alvarezii }\end{array}$ & Negatif & $\begin{array}{l}\text { Tutupan makroalga; } \\
\text { tutupan dan biomasa } \\
\text { lamun; kelimpahan } \\
\text { makrofauna }\end{array}$ & Eklof et al. (2005) \\
\hline Gracilaria salicornia & Negatif & $\begin{array}{l}\text { Perubahan makanan } \\
\text { ikan }\end{array}$ & Smith et al. (2004) \\
\hline
\end{tabular}



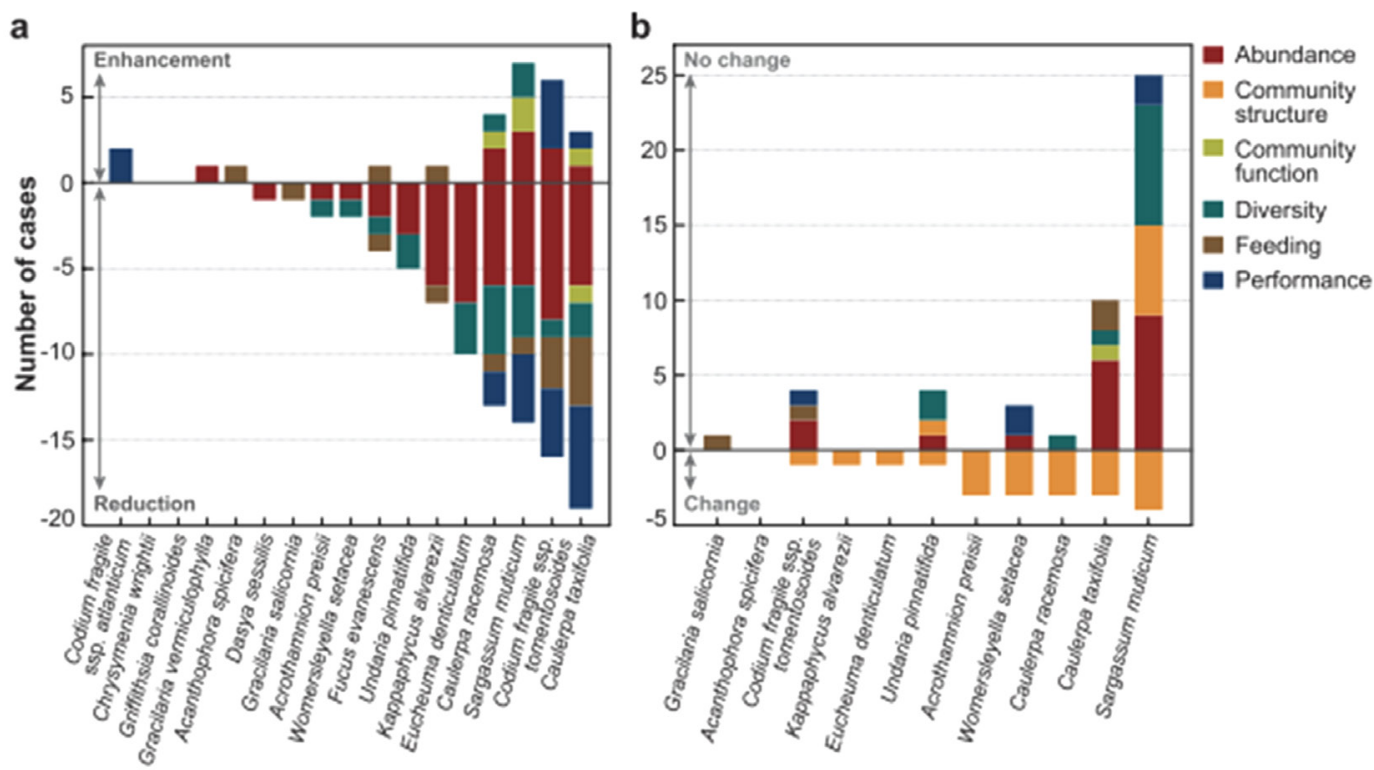

Gambar 2. Jumlah kasus fenomena makroalga introduksi (variabel respon tunggal). (a) dampak positif dan negatif makroalga introduksi dan (b) terjadinya perubahan atau tanpa perubahan ke spesies asli (Williams \& Smith, 2007).

Kehadiran Caulerpa taxifolia memberikan efek negatif terhadap kepadatan tunas lamun Cymodocea nodosa, dan penurunan produktifitas makroalga asli. Studi di pantai Mediterania, menunjukkan bahwa kehadiran C. taxifolia juga menyebabkan berkurangnya biomasa dan keragaman makroalga asli, serta menurunkan kelimpahan ikan. Namun, studi yang dilakukan di Perancis menunjukkan sebaliknya yaitu biomasa dan keragaman invertebrata tinggi. Racun pada metabolit sekunder C. taxifolia memiliki efeknegatif pada larva bulu babi di laboratorium (Schaffelke \& Hewitt, 2007).

Tutupan makroalga S. muticum pada musimnya dapat memonopoli cahaya, sehingga menghambat pertumbuhan makroalga asli dan lamun yang ada di sekitarnya. Selain itu, $S$. muticum juga menyebabkan menurunnya kelimpahan dan kekayaanjenis makroalga asli. Penurunan kelimpahan makroalga asli dapat menyebabkan menurunnya kelimpahan bulu babi Strongylocentrotus droebachiensis, fenomena ini terjadi karena bulu babi menghindari konsumsi $S$. muticum. Kondisi tersebut secara tidak langsung mendukung persistensi makroalga introduksi (Britton-Simmons, 2004; Schaffelke \& Hewitt, 2007). Codium fragile mampu menghambat perekrutan zoospora dari Laminaria sehingga menyebabkan terjadinya penurunan kelimpahan Laminaria. Monopoli ruang oleh $C$. fragile dapat menurunkan kelimpahan makroalga asli 
dan juvenil ikan (Schaffelke \& Hewitt, 2007).

Beberapa spesies makroalga merah (Acanthophora spicifera, Avrainvillea amadelpha, Gracilaria salicornia, Hypnea musciformis, Kappaphycus spp. dan Eucheuma spp.) telah terbentuk dengan kelimpahan tinggi dan menyebar di terumbu karang. Spesies tersebut memonopoli ruang dan produktivitas serta biomasanya juga meningkat (Smith, 2002). Permasalahan yang ditimbulkan oleh makroalga introduksi akan semakin parah apabila waktu terjadinya bersamaan dengan terjadinya blooming makroalga, sebagai contoh Dictyosphaeria cavernosa mengalami peningkatan biomasa yang sangat cepat pada saat terjadi peningkatan nutrien (Schaffelke \& Hewitt, 2007).

\section{Dampak Secara Ekonomi dan Sosial}

Informasi mengenai dampak makroalga introduksi secara ekonomi masih sangat sedikit, hal ini terkait dengan minimnya estimasi nilai ekonomi di sektor kelautan. Dampak makroalga introduksi secara ekonomi dan sosial dapat dikelompokkan menjadi dua yaitu dampak secara langsung dan tidak langsung. Dampak secara langsung tersebut antara lain: biaya-biaya hilangnya fungsi dan nilai ekosistem, daya dukung ekosistem dan kesehatan manusia. Sedangkan dampak secara tidak langsung meliputi: biaya manajemen (baik yang dilakukan oleh pemerintah dan non pemerintah), biaya penelitian untuk spesies introduksi, biaya untuk tindakan penghilangan dan pengendalian serta biaya untuk pendidikan dan kampanye penyuluhan (Schaffelke \& Hewitt, 2007).

Dampak secara ekonomi dari makroalga introduksi, salah satunya adalah biaya yang harus dikeluarkan untuk mengontrol dan upaya menyelesaikan masalah ekologi yang ditimbulkan oleh keberadaan makroalga introduksi. Sebagai contoh adalah di California, dimana membutuhkan dana sebesar 7,5 juta dolar amerika untuk mengontrol dan mengatasi dampak yang ditimbulkan oleh Caulerpa taxifolia, serta untuk biaya penelitian dan penyuluhan kesadaran masyarakat (Anderson, 2005).

Di beberapa negara, biaya untuk penelitian, mengontrol dan mengantisipasi dampak yang ditimbulkan oleh makroalga introduksi sudah banyak dilakukan. Biaya kegiatan pengelolaan umumnya terpisah dengan biaya penelitian. New Zealand menyediakan dana sebesar hampir US\$ 1 juta per tahun untuk penelitian keamanan laut. Amerika menyediakan dana penelitian terkait invasi biologi (termasuk di dalamnya spesies introduksi) sebesar US\$ 2,4 juta per tahun. Australia membentuk suatu badan yang bertugas mengelola hama di bidang kelautan, dalam kurun 3 tahun (2005-2007) disediakan dana sebesar US\$ 1,9 juta per tahun (Schaffelke \& Hewitt, 2007).

\section{TINDAKAN PENCEGAHAN}

Ada dua hal yang perlu dilakukan untuk memperkecil dampak yang ditimbulkan oleh makroalga introduksi, yaitu melalui manajemen dampak dan 
kebutuhan penelitian. Pengelolaan dampak makroalga introduksi harus bersinergi dengan strategi manajemen yang bertujuan untuk mencegah masuknya makroalga introduksi tersebut di tempat tertentu dan mengontrol atau memberantas makroalga yang sudah bersifat menyerang (invander) (Hewitt et al., 2004). Dampak dapat dihindari jika makroalga introduksi yang bersangkutan dapat dicegah untuk sampai pada jarak tertentu dari area yang dikelola. Dampak juga dapat diminimalkan jika tindakan pemberantasan atau pengontrolan dilakukan untuk mencegah kestabilan makroalga introduksi tersebut (Schaffelke \& Hewitt, 2007).

Penelitian terkait dampak makroalga introduksi harus fokus pada penelitian multidisiplin dengan pendekatan biologi, sosial dan ekonomi. Kerangka kerja perlu dikembangkan untuk memprediksi spesies yang mana yang cenderung untuk menyerang habitat tertentu. Mekanisme yang menyebabkan tingginya kelimpahan makroalga introduksi perlu diidentifikasi, termasuk peranan gangguan antropogenik dan perubahan iklim sebagai faktro pemicu. Variabel spasial dan temporan dari dampak perlu dikaji, yang akan memperbaiki pemahaman kerentanan dan adaptasi ekosistem (Schaffelke \& Hewitt, 2007).

\section{PENUTUP}

Saat ini, jumlah makroalga introduksi sebanyak 277 spesies dan jumlah tersebut akan terus bertambah.
Sebagian besar makroalga introduksi tersebut merupakan spesies invander yaitu spesies yang menjajah daerah di luar distribusi biogografi aslinya. Makroalga introduksi dapat masuk ke dalam ekosistem melalui beberapa perantara baik secara sengaja maupun tidak disengaja. Makroalga introduksi memberikan dampak secara ekologi dan ekonomi. Dampak yang ditimbulkan tersebut tidak selalu bersifat negatif, tetapi juga dapat memberikan positif (menguntungkan). Manajemen dampak dan penelitian multidisiplin sangat diperlukan untuk memperkecil dampak yang ditimbulkan oleh makroalga introduksi.

\section{DAFTAR PUSTAKA}

Anderson, L. W. J. 2005. California's response to Caulerpa taxifolia: a model for invasive species rapid response. Biol. Invasions 7: 1003-1016.

Arenas, F., R. M. Viejo and C. Fernandez. 2002. Density-dependent regularion in an invasive seaweed: responses at plant and modular levels. Journal of Ecology, 90: 820-829.

Argyrou, M., A. Demetropoulos and M. Hadjichristophorou. 1999. Expansion of the macroalga Caulerpa racemosa and changes in softbottom macrofaunal assemblages in Moni Bay, Cyprus. Oceanol. Acta 22:517-28. 
Britton-Simmons, K. H. 2004. Direct and indirect effects of the introduced alga Sargassum muticum on benthic, subtidal communities of Washington State, USA. Mar. Ecol. Progr. Ser. 277: 61-78.

Bulleri, F., F. Badalamenti, L. Ivesa, B. Mikac, L. Musco, A. Jaklin, A. Rattray, T. V. Fernandez and L. B. Cecchi. 2016. The effects of an invasise seaweed on native communities vary along a gradient of land-based human impacts. Peer J. 4:e1795; DOI 10.7717/peerj.1795.

Chisholm, J. R. M. and P. Moulin. 2003. Stimulation of nitrogen fixation in refractory organic sediments by Caulerpa taxifolia. Limnol. Oceanogr. 48:787-94.

Dumay, O., C. Fernandez and G. Pergent. 2002. Primary production and vegetative cycle in Posidonia oceanica when in competition with the green algae Caulerpa taxifolia and Caulerpa racemosa. J. Mar. Biol. Assoc. UK 82:379-87.

Eklof, J. S., M. de la Torre-Castro, L. Adelskold, N. S. Jiddawi and N. Kautsky. 2005. Differences in macrofaunal and seagrass assemblages in seagrass beds with and without seaweed farms. Estuar. Coastal Shelf Sci. 63:385-96.
Enge, S. 2012. Seaweed Invasions and novel chemical defenses. Thesis for the degree of doctor of philosophy. University of Gothenberg.

Ferrer, E., A. G. Garreta and M. A. Ribera. 1997. Effect of Caulerpa taxifolia on the productivity of two Mediterranean macrophytes. Mar. Ecol. Prog. Ser. 149:279-87.

Garbary, D, J., S. J. Fraser, C. Hubbard and K. Y. Kim. 2004. Codium fragile: Rhizomatous growth in the Zostera thief of eastern Canada. Helgol. Mar. Res. 58:141-46.

Hewitt, C. L., J. Willing, A. Bauckham, A. M. Cassidy, C. M. S. Cox, L. Jones and D. M. Wotton. 2004b. New Zealand Marine Biosecurity: delivering outcomes in a fluid environment. New Zeal. J. Mar. Fresh. Res. 38: 429-438.

Holdt, S. L. and S. Kraan. 2011. Bioactive compounds in seaweed: functional food applications and legislation. J. Appl. Phycol 23: 543-597.

Mack, R. N., D. Simberloff, W. M. Lonsdale, H. Evans, M. Clout and F. A. Bazzaz. 2000. Biotic invasions: causes, epidemiology, global consequences, and control. Ecological Applications 
10 (3): 689-710. DOI $10.2307 / 2641039$.

Morrissey, J., S. Kraan and M. D. Guiry. 2001. A guide to commercially important seaweeds on the Irish coast. Bord Iascaigh Mhara, Dublin, 66 pp.

Nyberg, C. D. 2007. Introduced marine macroalgae and habitat modifiers - their ecological role and significant attributes. Doctoral Thesis. ISBN: 9189677-33-1

Pedersen, M. F., P. A. Stæhr, T. Wernberg and M. S. Thomsen. 2005. Biomass dynamics of exotic Sargassum muticum and native Halidrys siliquosa in Limfjorden, Denmark - Implications of species replacements on turnover rates. Aquat. Bot. 83:31-47.

Piazzi, L., G. Ceccherelli and F. Cinelli. 2001. Threat to macroalgal diversity: effects of the introduced green alga Caulerpa racemosa in the Mediterranean. Mar. Ecol. Prog. Ser. 210:14959.

Piazzi, L., D. Balata, E. Cecchi and F. Cinelli. 2003. Co-occurrence of Caulerpa taxifolia and $C$. racemosa in the Mediterranean Sea: Interspecific interactions and influence on native macroalgal assemblages. Cryptogam. Algol. 24:233-43
Prathep, A., S. Pongparadon, A. Darakrai, B. Wichachucherd and S. Sinutok. 2011. Diversity and distribution of seaweed at Khanom-Mu Ko Thale Tai National Park, Nakhon Si Thammarat Province, Thailand. Songklanakarin Journal of Science and Technology 33 (6): 633-640.

Rasmussen R. S, and M. T. Morrissey. 2007. Marine biotechnology for production of food ingredients. In: Taylor SL (ed) Advances in food and nutrition research, 52: 237-292.

Satheesh, S. and S. G. Wesley. 2012. Diversity and distribution of seaweeds in the Kudankulam coastal waters. South-Eastern coast of India. Biodiversity Journal 3 (1):79-84.

Schaffelke, B. and C. L. Hewitt. 2007. Impacts of introduced seaweed. Botanica Marina, 50: 397-417. DOI 10.1515/BOT.2007.044

Smith, J. E., C. L. Hunter and C. M. Smith. 2002. Distribution and reproductive characteristics of nonindigenous and invasive marine algae in the Hawaiian Islands. Pacific Science, 56 (3): 299-315.

Smith, J. E., R. Most, T. Sauvage, C. Hunter, C. Squair and E. Conklin. 2004. Ecology of the invasive red alga Gracilaria 
salicornia in Waikiki and possible mitigation strategies. Pac. Sci. 58: 325-43.

Stæhr, P. A., M. F. Pedersen, M. S. Thomsen, T. Wernberg and D. Krause-Jensen. 2000. Invasion of Sargassum muticum in Limfjorden (Denmark) and its possible impact on the indigenous macroalgal community. Mar. Ecol. Prog. Ser. 207: 79-88.

Stimson, J., S. T. Larned and E. Conklin. 2001. Effects of herbivory, nutrient levels, and introduced algae on the distribution and abundance of the invasive macroalga Dictyosphaeria cavernosa in Kaneohe Bay, Hawaii. Coral Reefs 19: 34357.

Thomas, F., A. Box and J. Terrados. 2010. Effects of ivasive seaweeds on feeding preference and performance of a keystone Meditarranean herbivore. Biol. Invasions : 1-2. DOI 10.1007/ s10530-010-9913-6.

Thomsen, M. S., P. A. Staehr, L. Nejrup and D. R. Scheil. 2013. Effects of the invasive macroalgae Gracilaria vermiculophylla on two co-occurring foundation species and associated invertebrates. Aquatic Invasions, 8 (2): 133-145.
Wikstrom, S. A., M. B. Steinarsdottir, L. Kautsky and H. Pavia. 2006. Increased chemical resistance explains low herbivore colonization of introduced seaweed. Oecologia 148:593601

Williams, S. L. and E. D. Grosholz. 2002. Preliminary reports from the Caulerpa taxifolia invasion in southern California. Mar. Ecol. Prog. Ser. 233:307-10.

Williams, S. L. and J. E. Smith. 2007. A global review of the distribution, taxonomy and impacts of introduced seaweeds. Annual Review of Ecology, Evolution and Systematics 38:327-359.

York, P. H., D. J. Booth, T. M. Glasby and B. C. Pease. 2006. Fish assemblages in habitats dominated by Caulerpa taxifolia and native seagrasses in south-eastern Australia. Mar. Ecol. Prog. Ser. 312: 223-234. 